\title{
Parents in transition: Experiences of parents of young people with a liver transplant transferring to adult services
}

DOI:

10.1111/petr. 12760

\section{Document Version}

Accepted author manuscript

Link to publication record in Manchester Research Explorer

\section{Citation for published version (APA):}

Wright, J., Elwell, L., Mcdonagh, J., Kelly, D. A., \& Wray, J. (2017). Parents in transition: Experiences of parents of young people with a liver transplant transferring to adult services. Pediatric transplantation, 21(1). https://doi.org/10.1111/petr.12760

\section{Published in:}

Pediatric transplantation

\section{Citing this paper}

Please note that where the full-text provided on Manchester Research Explorer is the Author Accepted Manuscript or Proof version this may differ from the final Published version. If citing, it is advised that you check and use the publisher's definitive version.

\section{General rights}

Copyright and moral rights for the publications made accessible in the Research Explorer are retained by the authors and/or other copyright owners and it is a condition of accessing publications that users recognise and abide by the legal requirements associated with these rights.

\section{Takedown policy}

If you believe that this document breaches copyright please refer to the University of Manchester's Takedown Procedures [http://man.ac.uk/04Y6Bo] or contact uml.scholarlycommunications@manchester.ac.uk providing relevant details, so we can investigate your claim.

\section{OPEN ACCESS}


Parents in transition: Experiences of parents of young people with a liver transplant transferring to adult services

$$
\text { Wright } \mathrm{J}^{1} \text {, Elwell } \mathrm{L}^{1,2}, \mathrm{McDonagh}^{\mathrm{J}} \mathrm{E}^{3} \text {, Kelly } \mathrm{DA}^{1} \text {, Wray } \mathrm{J}^{4}
$$

1Liver Unit, Birmingham Children's Hospital NHS Foundation Trust, United Kingdom

2University of Birmingham, United Kingdom

${ }^{3}$ Centre for Musculoskeletal Research, University of Manchester, United Kingdom

${ }^{4}$ Critical Care and Cardiorespiratory Division, Great Ormond Street Hospital for Children NHS Foundation Trust, United Kingdom

Corresponding author: Dr Jo Wray

Contact e-mail: jo.wray@gosh.nhs.uk

Contact telephone: +442078297822

Contact address: Great Ormond Street Hospital for Children NHS Foundation Trust

Great Ormond Street, London WC1N 3JH

Key words: parents, liver transplant, transition

Running title: Parents in transition 


\begin{abstract}
Background

Predictors of successful transition from paediatric to adult services include ability to selfmanage and engage with healthcare services. Parents have a key role in healthcare management throughout childhood and adolescence including encouraging development of self-management skills in their children. Transition to adult services can be challenging for parents and young people, yet parents' views regarding transition remain largely unexplored.

Methods
\end{abstract}

Nine parents of paediatric liver transplant recipients (15.2-25.1 years) participated in semistructured interviews. Interviews were analysed using Interpretative Phenomenological Analysis.

Results

Analysis revealed three key themes: 'emotional impact of transplantation', 'protection versus independence' and 'ending relationships and changing roles'. Parents expressed the dichotomous nature of the desire to promote independence in their child while still maintaining control and protection, and discussed how changing roles and relationships were difficult to navigate.

\title{
Conclusion
}

Parents are important facilitators of young people's development of self-management skills for successful transfer to adult services. Parents should be supported to move from a 'managerial' to a 'supervisory' role during transition to help young people engage independently with the healthcare team. Findings support the development of interventions 
for parents to emphasise their role in transition and guide the transfer of self-management skills from parent to young person. 


\section{Introduction}

Approximately $15 \%$ of adolescents have a long-term health condition (1) which can significantly impact upon their daily lives. Although relatively rare, there are approximately 600 adolescent/young adult survivors (aged 15-25 years) of liver transplantation in the UK,(2) all of whom require life-long medication and regular, long-term follow-up at a specialist centre. For these young people, their parents have had a significant role in managing their health condition and have been key contributors during their time in paediatric services. As young people reach adolescence there can be a struggle as they seek greater autonomy and independence at a time when parents may not be ready to let go, nor the young people equipped with the skills to self-manage. Findings show that coping with their child's newly acquired skills of autonomy can be difficult for parents and further support from health professionals during this time is required.(3)

Adolescents with a liver transplant not only have to contend with learning to manage their own condition as they enter young adulthood, but they also have to navigate the change in healthcare settings which occurs as they outgrow paediatrics and require follow-up in adult services. Transition involves preparing, adapting and moving to adult services in a multifaceted process whereby the medical, educational, vocational and psychosocial needs of the patient are incorporated into a purposeful, planned programme.(4) Parents of a child with a liver transplant have an important role in supporting their child through transition. However, it is important to acknowledge that parents also go through an important transition of their own during this time (5) as the change in healthcare setting has an impact on their existing roles, responsibilities and relationships. As adolescence and transition proceed, roles and responsibilities shift as young people develop skills of self-management 
and progress through emerging adulthood. Parents have to learn to support the increasing autonomy of their child while also managing their feelings about their own transition. Findings suggest that transition can have more of an impact on parents than on young people.(6)

As the demands on transition services have grown, understanding the components which make transition successful has been essential. Research has identified that dedicated clinics, beginning preparation at an early stage and knowledge and skills training for young people are key components of successful transition programmes. (7-10) Effective transition from parental to youth health management should also be considered a facilitator of successful transition (11) given the important role that parents have in helping their young person develop self-management skills and gain independence.

For young people with a liver transplant, a vital step in managing their condition is assuming responsibility for medical management, which usually happens gradually over time with varying levels of guidance and support from both parents and healthcare providers.(12) However, non-adherence to medications and failure to attend clinic appointments have been shown to increase following transfer to adult services $(13,14)$ and as a result, these young people are at greater risk of graft loss and death.(15) In light of this, it is important to explore how to better support young people with the acquisition of self-management skills.(16) Throughout their child's life parents have taken responsibility for medical management and facilitating engagement with medical services and therefore have a key role in supporting their children to learn to self-manage as they grow-up. 
The body of literature exploring the psychosocial issues of parents of an adolescent with a chronic illness (3) and parental experiences of transition (17-19) is growing. Parents of liver transplant recipients have reported "moderate" concern about transition using quantitative methodology but demonstrate limited knowledge about the process.(20) However, experiences of transition have been rarely explored with parents of paediatric liver transplant recipients. Qualitative methodology allows for a more in-depth exploration and insight to be gained than quantitative methods and provides the opportunity to gain a greater understanding of the impact of transition on parents. As part of a wider study of transition in liver transplantation the aim of the current study was to explore, using qualitative methodology, parental views and experiences of transition. Understanding transition from the perspective of parents will provide us with a clearer view of how we can better support both young people and parents through transition, as well as increasing our knowledge about the shifting roles and responsibilities of emerging adulthood in the context of liver transplantation.

\section{Methods}

\section{Sampling and participants}

Parents were eligible for inclusion if they had a child who had undergone a liver transplant in childhood and who had transferred to adult services within the previous five years or were expected to move to adult services within 12 months. In both paediatric centres patients could transfer to adult services from the age of 16 years, with an individualised approach being adopted for the age of transfer, with most 
young people transferring when they had completed secondary education. Potential participants who met inclusion criteria $(n=18)$ were invited to take part in an interview by a member of the clinical team via letter. The researcher telephoned those who had been invited and if parents wanted to take part a suitable time and place for the interview was arranged. Although no parent declined participation, nine parents did not take part either because they were unable to attend the routine outpatient appointment with their child or because the researcher could not contact the parent. All participants were provided with an information sheet in advance of the appointment and gave informed consent prior to taking part, as per UK ethical guidelines.

Nine parents ( 6 female, 3 male) were recruited for interview from four liver unit centres. Four were parents of a young person pre-transfer to adult services but in transition and five were parents of a young person post-transfer. Young people were a mean age of $19.7 \pm 3.2$ years $(15.2-25.1)$ at the time their parents were interviewed. Young people were transplanted a mean of $10.2 \pm 7.6$ years $(1.2-20.3)$ years previously. Six young people had been transplanted due to chronic liver disease and three were transplanted due to acute liver failure. Demographic information for the parents and young people can be found in Table 1.

\section{Design and setting}

A qualitative semi-structured interview design was chosen to allow for exploration of the experiences of transition for parents.(21) Interviews were conducted when parents 
attended a LTX clinic with their children for routine clinic appointments at one of four sites, two of which were paediatric tertiary hospitals and two were adult hospitals. All of the hospitals had a transition programme. Interviews took place in a private consultation room. Two further interviews with parents of young people under paediatric follow-up took place via the telephone. Interviews lasted for 25-55 minutes (mean: 42 minutes) and young people were not present during the interview with their parents.

\section{Reflexivity}

The interviews were conducted by the first author (a female health psychology student) and analysed by the first and second (a female health psychologist with a background in qualitative methodology) authors. Both authors had experience of working with families in health settings and an in-depth knowledge of the field of transition which contributed not only to the data collection but also to the interpretative stage of analysis and the credibility of the research. Each researcher's background, experiences and beliefs contributed to and were integral to the interpretative process and allowed for a meaningful perspective of experiences to be gained .(22)

\section{Procedure}

Each interview began with a brief introduction to the purpose of the study and format of the interview. Participants were given the opportunity to ask questions if they wished. The focus of the interview was about being a parent of a young person growing up with a liver transplant and their own experiences of the transition process. The interviewer adopted a minimalist passive approach during interviews to encourage a narrative response. An interview schedule was used by the interviewer to guide question topics, drawing on the 
literature and the input of the wider research team which included experts in liver transplantation and adolescent medicine. Topics included their experience of their child's illness or transplant, their understanding and experiences of transition and what would, or had, helped during the process of transition (Table 2). Due to the exploratory nature of the study interviews were flexible and guided by the interviewee rather than interviewer, with the interview schedule reflecting areas of interest rather than being employed prescriptively. The interviews were conducted between November 2011 and February 2013. Interviews were audio recorded and subsequently transcribed verbatim.

\section{Ethical issues}

Ethical approval was obtained from an NHS Research Ethics Committee and the research adhered to the Trusts' individual research and development protocols. The anonymity of participants was protected during transcription and analysis through the use of participant numerical codes. Informed consent was sought for the digital recording of interviews and for interview content to be used in publications. Participants were informed that they could withdraw from the study at any time and that this would not have an impact on any aspect of care provided to their child or to them.

\section{Data analysis}

Interviews were analysed according to the principles of interpretative phenomenological analysis (IPA).(23) IPA focuses on the lived experience of the participant and endeavours to make sense of the meanings of events or experiences to the participants themselves. The procedure of analysis closely followed the four- 
step process outlined by Smith \& Osborn.(24) Interviews were firstly transcribed verbatim. Each transcript was read and re-read by both the first and second author in order to become familiar with interview content. Notes were made by the researchers of anything of significance. The transcript was then coded individually by both researchers using initial notes for guidance. Themes emerging from the data were identified and themes that were meaningfully associated were clustered together resulting in a list of superordinate and subordinate themes, with the whole process of emergent themes and checking back with the transcript developing cyclically. Having completed the first transcript, the process was then repeated with subsequent transcripts by the first and second author independently.

The authors met periodically (approximately every 2-3 weeks) during the analysis phase to discuss emerging themes and a final consolidated list of master themes was produced. Co-analysis facilitated the on-going double hermeneutic process of interpretation throughout analysis and allowed for deeper meaning and interpretation to be drawn from the data as consensus was reached. For example, when the authors met to discuss emerging themes, the process of interpretation was enhanced as each author was compelled to consider not only how they made sense of the participants making sense of their experiences but also how the other author had made sense of the participants' experiences in order to identify meaningful codes and themes. Wider discussion of the data, interpretation and themes also took place during quarterly team meetings or more frequently if necessary with other research team members who had expertise in liver transplantation and adolescent medicine in order to ensure 
the credibility of the findings. Qualitative analysis software was used throughout to support the analytical process (NVivo version 9.2).

\section{Results}

Analysis of the interviews revealed three main themes: "emotional impact of transplantation", "protection versus independence" and "ending relationships and changing roles". These themes will be discussed further below.

\section{Emotional impact of transplantation}

When discussing life as a parent of a child with a liver transplant, parents shared experiences of the subsequent impact this had emotionally. Parents reflected on how going through the process of transplant had been an unpredictable, anxious and upsetting time. They also talked about how the transplant had changed their lives, both positively and negatively. For instance one parent discussed this in relation to the impact upon other family members:

Mother: "I think it's quite traumatic because you've got lots of ups and lots of downs. Life's not normal like it is for other people. And if you've got other children it's hard to keep everything balanced and normal because you're forever in and out of the hospital." Interviewer: "How do you think that affects the other children?" Mother: "I do think it's hard, and I do think it's very difficult to get into a routine, when you've got other kids because you could be away for a long 
period of time and then you come back again and then they all want your attention, and so, everything's a bit mental. "

Mother of a young person (female, age 25) post-transfer

All of the parents discussed the 'ups' and 'downs' of life with a child with a liver transplant. Although the transplant had been a life-saving operation, parents were aware that they were effectively swapping one set of problems for another and the after effect of the transplant was lifelong management of a long-term condition. Parents reflected that life had often been difficult but tried to draw positive aspects out of the experience.

"Oh, it's not saying you don't have difficult days but I think we manage alright. [We] just try and be positive. You do get a bit fed up, I mean you really do. And there's kids worse than [my child] and there's parents [who] lost theirs, so you try and, try and, she's still here, you know what I mean?" Father of a young person (female, age 21) post-transfer Parents had, understandably, been affected by deaths of other patients during their child's time as a patient. For the parents, reflecting on those difficult experiences or the difficult experiences of the other families gave them a sense of perspective and often helped them to overcome the difficulties faced in their own everyday life. For some parents, discussing the negative impact on life as a result of the transplant was associated with guilt when considering the difficult experiences of others.

One parent shared her experience of her child being on the transplant list and the difficulties of waiting for the transplant to happen. This experience was shrouded in 
anxiety and for the family meant that normal activities such as days out or holidays either didn't happen, or required such meticulous planning that they ceased to be enjoyable.

"So it seems to have a $-y$ 'know, to have a big impact on his life, our lives. You can't really go away for holidays so the most you can do is perhaps a weekend somewhere. And, so everything's on hold if you like, your whole life is on hold...It is difficult, as a family, y'know you can't make many long-term plans... You just didn't want to plan anything in case the phone rang. You always have to make sure there's a plan B, there's somebody available who wouldn't have been drinking who can just drop everything and take us. And you get paranoid, about, $y^{\prime}$ know, have I got my mobile phone with me when I go out just in case they try to get hold of us?"

Mother of a young person (male, age 18) pre-transfer

Protection versus independence

Parents discussed the changing roles of their involvement in their child's care as the young people navigated emerging adulthood, with interviews revealing a sense of conflict over wanting to protect their child and yet also wanting them to be independent. Parents were acutely aware of the need to let their children be independent, but many elements of the adult world were out of their control, which they found distressing.

"When it's a sixteen year old they're still not actually an adult. So, your, whilst in some ways I treat him as an adult and he should be treated as an adult as regard to his care and his future because he's going to be taking personal 
responsibility for it, as a parent I probably don't want him to be in with influences which could be detrimental to him you know."

Mother of a young person (male, age 16) pre-transfer

Parents discussed their worry over how their child would cope with being an adult with a liver transplant but they talked about how important it was to have balance and allow young people to be independent.

"it is difficult, because you never think anybody could look after your child the way you've looked after them. But you have to let 'em. You have to let them try and do things for themselves. And, I don't, wrap her up in cotton wool to be fair, I do check her a bit more, ring a bit more but I let her do things" Mother of a young person (female, age 25) post-transfer Although parents expressed their desire to allow their children to be independent, for a lot of the parents this was very difficult to do in practice. They had doubts about their child's ability to manage their own care in adult services as they felt they still had a very active role in supporting them to manage their condition.

"We are very protective, even now. Because even though he's back to normal, and with normal people, we have to look after him anyway, we have to remind him all the time, remind him to take medicines to time."

Father of a young person (male, age 18) pre-transfer 
Concerns about their child's ability to cope in adult services were particularly highlighted as it was expected that during transition young people would need to begin to take a more active role in their healthcare and would be expected to be accountable for themselves. This concerned parents as they felt they may not be privy to important information about their child's care. Parents worried that their child either would not share information with them, or would not listen or ask the right questions during their clinic appointments. Furthermore, parents identified themselves as having an important role in protecting their children from bad news and being there to support them during difficult times. Parents felt that this role would be taken away from them once in adult services.

"What worries me more than anything I think is, because, when she was having the transplant and they told us, they didn't really tell [the patient]. Now to me, they said we should be honest with her but I felt, only to a degree can I be honest with her. You know they said if she turns round and says "Am I going to die?" you must tell her the truth. Well, there's no way I would have been able to do [that] at nine. I think what bothers me more than anything [is] if things start to reject or things start to go wrong that they will actually tell her and not us. Up to now, they always tell us and we tell her, although she's got older, there's talk, you know, she's more in on the conversation. So, they can only be scared to a certain extent can't they then because they don't know the full extent of it and I think that's what will bother me most, is them talking directly to her at seventeen, eighteen say, if they're "Oh it's ninety-five percent survival" or "ninety-five percent not", that they would tell, that they'd have to tell her first do you know what I mean? Because I would just worry how she would react." 
Ending relationships and changing roles

Parents discussed the strong relationships that had developed during their time in paediatric services. Most of the young people had been patients since early childhood and parents discussed perceiving the paediatric teams as family.

"The [paediatric] liver transplant team, and the nurses on the ward as well, they've got to know you and it's more or less like a family, you know. They know the ins and outs of him and he knows everybody there as well."

Father of a young person (male, age 16) post-transfer

Parents viewed the paediatric teams as an important part of their support network and as being integral to coping with the emotional impact of their child undergoing transplantation. Parents associated paediatric services with positive relationships where they gained support from staff members to help them through difficult times.

"When you've been through an event like that with the certain staff you do get some sort of a bond because they've seen you at your very worst when you've been running round corridors crying your eyes out and things so you get a sort of bond with people which you would lose."

Mother of a young person (male, age 16) pre-transfer 
Most of the parents talked about the inevitability of transfer and although they knew it was something which needed to happen, they felt comforted by the familiarity of paediatric services. Adult services represented anonymity and being unknown.

"Once they said, 'OK, you need to fly the nest,' so to speak, it was, right well, we understand that, we can't stay here forever, much as we love you all, we know, she's not a child. And, we have to go...Leaving the care that we'd had there, and the relationship that we'd got with [her] consultant, to have to surrender that, to the anonymity of a bigger hospital, you think, well they don't know anything about her here."

Mother of a young person (female, age 21) post-transfer

For parents, the loss of this relationship at the time of transfer also seemed to represent a termination of their role as a key player in their child's condition as parents were aware that they might be treated different by clinicians in adult services as the focus of care shifted. The idea of taking more of a 'backseat role' was anxiety provoking. Parents talked about feeling side-lined by adult clinicians who positively encouraged the young person to be the focus of consultations and, therefore, their role was redundant.

"It's completely different because they weren't talking to me, in the adults, they're talking to her. And because I'm used to, I know I do speak for her sometimes, but you just do, it was as if, 'you be quiet, she needs to talk, she's an adult now. 'I thought, but hang on, she's not."

Mother of a young person (female, age 22) post-transfer 
Parents identified contact with the adult centre prior to transfer and being provided with the opportunity to start to develop new relationships as important factors in the transition process.

"Therefore the fact that we knew people here - simply because we'd met them already and that was a really helpful start to our life in the adult world". Mother of a young person (female, age 21) post-transfer.

In contrast, not providing these opportunities was perceived as hindering a good transition. The following quote from a mother whose child was transferring imminently illustrates the potential for transition to be a negative experience.

"And a letter arrived at home, just stating, "from May you'll be transferred over to adult's". That was it. They've not given him the name of any of his doctors who are going to be looking after him once he's transferred, who's going to be in charge of his transplant, nothing. Just a letter saying erm "sorry I missed you in clinic." Short and sweet. We were not very happy about that...... Transition over to adults...... it's been rubbish. And, it's something they really need to look at."

Mother of young person (male, age 18), pre-transfer

\section{Discussion}

The purpose of the current study was to understand parental experiences of transition to support both parents and young people to self-manage and engage with the healthcare system during the transition process. This study is unique in liver transplantation - although there have been quantitative studies exploring parent perspectives of transition to adult care for parents of liver transplant recipients, (20) this study is the first to examine parents' 
experiences of transition both pre and post-transfer using qualitative methodology, specifically IPA. Use of a qualitative approach provided a more in-depth insight and a greater understanding of the impact of transition on parents than obtained in previous quantitative studies. The study also adds to and complements the growing body of qualitative research into transition and the role of parents of young people with a long-term condition.

Parents discussed the emotional impact that having a child with a liver transplant had on their lives. The authors felt it was important to include this narrative as, although not specifically about transition, it provided important context about parental roles and helped to explain difficulties in letting-go in later life when considering how much parents had emotionally invested during the whole journey. Parents in the current study reported unpredictability, persistent anxiety, the need for excessive planning and missing out on fun family activities, which are factors reported by parents of other children with a long-term condition.(25) In Coffey's meta-synthesis, parents reported "living worried" and that hyperorganisation came first and foremost, rendering some aspects of family life which should have been enjoyable as a strain.

In the current study, parents demonstrated difficulties in 'letting-go' and delegating responsibility for their child's health to their child. This is a common finding in the literature, with studies showing that parents of young people with a long-term illness find the whole process of emerging adulthood, the acquisition of autonomy and transition a difficult time. $(3,26)$ The shift in parental role and the impact on parents has also been identified previously in a study of parents of young people who had undergone liver transplantation 
and had started the transition process but had not yet transferred. (27) Parents expressed a need to protect their children, something which was threatened by the transition process and generated feelings of being excluded from their child's care. This fear has been articulated in studies of other populations $(17,28)$ in which parents reported feeling anxious that transition to adult services would lead to less involvement in their child's care. Research suggests that parents of children with a long-term condition have specific information needs which are an important coping strategy for parents in order to manage anxiety and uncertainty and regain a sense of control.(29, 30) For parents, transition can be a time where being privy to information about their child's health can change, thereby taking away their ability to assert control and ultimately provide protection for their child. Parents who have spent a lifetime protecting their child are likely to find this change in role a difficult adjustment and express feelings of grief and loss during the transition process.(31) This highlights the need for effective communication between parents, the young person and health professionals so that all parties can feel supported during this time.

It is also important to consider the impact of this shifting dynamic on the young people themselves. For some young people, perceived overprotection or excessive control can be unhelpful and result in a desire to take control by force, which is often perceived as 'teenage rebellion' or a withdrawal from responsibility altogether.(19),(32) These are undesirable outcomes and have important implications for a young person's ability to self-manage in the future. Therefore, it is imperative that parents can support their young people appropriately as they gain independence and research suggests that parents are seeking support from health professionals in order to do this.(33) Methods commonly adopted by health professionals to increase patient engagement, such as motivational interviewing for young 
people and involvement in shared decision making $(34,35)$ may offer ways in which parents can support young people as they gain independence.

Along with the shift in the role of the parent from 'manager' to 'supervisor', [33] a shift in the relationships between the health professionals and the parents occurs following transfer to adult services. Paediatric services are family centred and parents described the closeness of the relationships that they had formed with the paediatric team and the importance of this for their own coping. Parents saw themselves as key members of the healthcare relationship, often involved in making the decisions about their child's health and treatments. In adult services parents do not have this role to the same degree, which challenges their need to protect their child and removes the sense of control previously experienced in paediatric services. This finding links to previous findings of parents' experiences of having a child with a long-term condition, where parents have demonstrated a need to be partners in their child's care.(36) When this is removed they can become hyper-vigilant and overly-assertive $(33,37)$ which may lead to feelings of frustration and an overwhelming urge to "protect" their child, potentially hindering their child's acquisition of independent skills of self-management. It is therefore important that transition services acknowledge how difficult the shift in dynamics, relationships and control can be for parents and provide support through this process and encourage inclusion in other ways.

Limitations and implications for future study

As data were collected when young people attended routine clinic appointments, some parents were not recruited as they did not regularly attend clinic with their child. As a consequence, the parents recruited may have represented a group who were generally 
more anxious about being involved in their child's care. This might particularly be the case with parents who attended with their child in adult services. On the other hand, it may have been that the parents who attended clinic were more supportive and appropriately involved in their child's care. There are a number of other factors which might explain parents' levels of involvement in clinic appointments, including their relationship with their child, whether or not their child was willing to share information about their medical care and appointments with them and/or wanted their parent to accompany them to clinic, the distance that parents lived from the hospital and the practicalities of them attending clinic with their child (particularly when their child was living independently). It is also possible that it was unusual for parents to attend clinic with their child but they had done so for the purposes of the study. On reflection, it would have been useful to find out whether they would normally attend outpatient clinic with their child as this may have revealed more about their relationship or role in their child's healthcare. As a result, the study may not have represented parents who felt more relaxed about transition and therefore the opportunity to explore the factors associated with positive parental transition experiences may have been missed. Alternatively, the study may also not have represented those parents who had had a negative transition experience either through being excluded by their child or due to logistical challenges of attending clinic with their child Whilst the age range of young people in the current study was quite large, the World Health Organisation definition of young people spans $10-24$ years,(38) reflecting adolescent and young adult developmental stages whilst at the same time being consistent with the transition process starting in early adolescence and completed in young adulthood. This 
age range captures developmentally appropriate care and it is important to recognise that any transition intervention needs to consider the entirety of this age range.

Previous research into the implementation of transitional care guidance, which included parents of young people with liver transplants, found that parent satisfaction with care was significantly greater in those clinics with transition programmes (39), indicating the benefit of a transition programme for parents as well as young people. Research exploring the parent-child relationship in young people with a long-term condition demonstrates the persistence of the maternal role in decision-making into early adulthood and adult care where mothers provide important cognitive, practical and emotional support.(40) It is therefore important to acknowledge the on-going maternal role for both mothers and for young people and not to assume that as adulthood commences, the need for parental support comes to an end. There is also a need for more research about the role of fathers, who have been shown to have different perspectives from mothers about the process of autonomy and concerns about different aspects of their child's life. (3)

With the successful implementation of programmes to support young people through the transition process, (41-43) it is also important that transitional care interventions include parents as well as young people. Parents and young people would benefit from programmes which help them to define and respond appropriately to their shifting roles and responsibilities. Successful interventions incorporate educational components to support parents in assisting their adolescent child to become autonomous. $(9,44)$ Akre and colleagues (44) also found that parents may benefit from peer support during this process. The findings of the current study support the need for the development of a programme to 
support parents as their child develops autonomy. One format for delivering such an intervention would be a group workshop so that parents might benefit from peer-to-peer interaction and support when considering the emotional impact of being a parent of a young person with a liver transplant. A recent intervention using parents as 'transition experts' showed that a parent-led, peer support group provided informational, emotional and affirmational support during transition which resulted in parents feeling more knowledgeable and included in the transition process.(45) Studies such as this demonstrate the important role parents have as experts in their child's healthcare management and transition and highlight that it is vital that interventions are designed to acknowledge the important role of parents and support the transfer of skills from parent to young person.

\section{Conclusion}

Parents are important facilitators of young people's development of self-management skills for successful transfer to adult services. In order to help young people engage with the health care team parents should be supported to move from a 'managerial' role to a 'supervisory' role during the process of transition. Transition programmes have demonstrated benefits for parents as well as for young people and the current study emphasises the need for the development, implementation and evaluation of interventions to support parents as their children become more autonomous. Future research should focus on identifying what type of interventions parents find helpful and how such interventions should be delivered to optimise effectiveness for both parents and young people.

\section{Acknowledgements and funding}


The authors thank Sister Monica Smith, Philippa Lewis, Carla Lloyd and Dr Patrick McKiernan from Birmingham Children's Hospital, UK; Professor David Adams, Dr James Ferguson and Bridget Gunson from the Queen Elizabeth Hospital, Birmingham, UK; Dr Patricia McClean, Sister Lynne Henderson and Peter Sewell from the Leeds General Infirmary, UK; and Sister Jacqueline Jennings from St James' Hospital, Leeds, UK for their help in identifying and recruiting the patients. We also thank the parents who took part for their valuable contribution to the study and Children's Liver Disease Foundation for their input as the representative for Patient and Public Involvement.

This study was funded by a research grant from BSPGHAN/CORE.

\section{Author contribution}

Jessica Wright: collection, analysis and interpretation of data; drafting of manuscript, approval of final manuscript

Laura Ellwell: analysis and interpretation of data; critical revision of manuscript; approval of final manuscript

Janet McDonagh: study design and concept; critical revision of manuscript; approval of final manuscript

Deirdre Kelly: study design and concept; critical revision of manuscript; approval of final manuscript Jo Wray: study design and concept; critical revision of manuscript; approval of final manuscript 


\section{References}

1. Brooks F, Magnusson J, Klemera E, Spencer N, Morgan A. HBSC England National Report: Health Behaviourin School Aged Children (HBSC): World Health Organisation Collaborative Cross National Study. . Hatfield: University of Hertfordshire; 2011.

2. PERISANIDOU L. NHS Blood and Transplant. 2016.

3. AKRE C, SURIS JC. From controlling to letting go: what are the psychosocial needs of parents of adolescents with a chronic illness? Health Educ Res 2014: 29: 764-772.

4. BLUM RW, GARELL D, HODGMAN CH, et al. Transition from child-centered to adult health-care systems for adolescents with chronic conditions. A position paper of the Society for Adolescent Medicine. J Adolesc Health 1993: 14: 570-576.

5. KLOEP M, HENDRY LB. Letting go or holding on? Parents' perceptions of their relationships with their children during emerging adulthood. Br J Dev Psychol 2010: 28: 817-834.

6. GEERTS E, VAN DE WIEL H, TAMMINGA R. A pilot study on the effects of the transition of paediatric to adult health care in patients with haemophilia and in their parents: patient and parent worries, parental illness-related distress and health-related Quality of Life. Haemophilia 2008: 14: 1007-1013.

7. CROWLEY R, WOLFE I, LOCK K, MCKEE M. Improving the transition between paediatric and adult healthcare: a systematic review. Arch Dis Child 2011: 96: 548-553.

8. LUGASI T, ACHILLE M, STEVENSON M. Patients' perspective on factors that facilitate transition from child-centered to adult-centered health care: a theory integrated metasummary of quantitative and qualitative studies. J Adolesc Health 2011: 48: 429-440.

9. MCDONAGH JE, SOUTHWOOD TR, SHAW KL, BRITISH SOCIETY OF P, ADOLESCENT R. The impact of a coordinated transitional care programme on adolescents with juvenile idiopathic arthritis.

Rheumatology (Oxford) 2007: 46: 161-168.

10. SURIS JC, AKRE C. Key elements for, and indicators of, a successful transition: an international Delphi study. J Adolesc Health 2015: 56: 612-618.

11. REED-KNIGHT B, BLOUNT RL, GILLELAND J. The transition of health care responsibility from parents to youth diagnosed with chronic illness: a developmental systems perspective. Fam Syst Health 2014: 32: 219-234.

12. Lotstein DS, GHandour R, CASH A, McGuire E, StrickLand B, NeWACHeCK P. Planning for health care transitions: results from the 2005-2006 National Survey of Children With Special Health Care Needs. Pediatrics 2009: 123: e145-152.

13. Annunziato RA, EmRe S, Shneider B, Barton C, Dugan CA, Shemesh E. Adherence and medical outcomes in pediatric liver transplant recipients who transition to adult services. Pediatr Transplant 2007: 11: 608-614.

14. FREDERICKS EM, DORE-STITES D, Well A, et al. Assessment of transition readiness skills and adherence in pediatric liver transplant recipients. Pediatr Transplant 2010: 14: 944-953.

15. POLLOCK-BARZIV SM, FINKELSTEIN Y, MANLHIOT C, et al. Variability in tacrolimus blood levels increases the risk of late rejection and graft loss after solid organ transplantation in older children. Pediatr Transplant 2010: 14: 968-975.

16. WRIGHT J, ELWELL L, MCDONAGH JE, KelLY DA, WRAY J. 'It's hard but you've just gotta get on with it' - The experiences of growing-up with a liver transplant. Psychol Health 2015: 30: 1129-1145.

17. AlLen D, CHANNon S, LoWes L, AtWeLl C, LANE C. Behind the scenes: the changing roles of parents in the transition from child to adult diabetes service. Diabet Med 2011: 28: 994-1000.

18. Anthony SJ, Martin K, Drabble A, Seifert-Hansen M, Dipchand Al, Kaufman M. Perceptions of transitional care needs and experiences in pediatric heart transplant recipients. Am J Transplant 2009: 9: 614-619.

19. Clarizia na, Chahal N, Manlhiot C, Kilburn J, Redington an, McCrindle BW. Transition to adult health care for adolescents and young adults with congenital heart disease: perspectives of the patient, parent and health care provider. Can J Cardiol 2009: 25: e317-322. 
20. FREDERICKS EM, Dore-STITES D, LopeZ MJ, et al. Transition of pediatric liver transplant recipients to adult care: patient and parent perspectives. Pediatr Transplant 2011: 15: 414-424.

21. KVALE S, BRINKMANN S. InterViews: Learning the craft of qualitative research interviewing. Thousand Oaks, CA: Sage, 2008.

22. HORSBURGH D. Evaluation of qualitative research. J Clin Nurs 2003: 12: 307-312.

23. SMITH JA. Beyond the divide between cognition and discourse: using interpretative phenomenological analysis in health psychology Psychology \& Health 1996: 11: 261-271.

24. SMITH JA, OSBORN M. Interpretative phenomenological analysis. In: SMITH JA, ed. Qualitative psychology: a practical guide to research methods. London: Taylor \& Francis, 2003. pp. 53-80.

25. COFFEY JS. Parenting a child with chronic illness: a metasynthesis. Pediatr Nurs 2006: 32: 51-

59.

26. WiLlaAMS B, MUKHOPADHYAY S, DOWELL J, COYLE J. From child to adult: an exploration of shifting family roles and responsibilities in managing physiotherapy for cystic fibrosis. Soc Sci Med 2007: 65: 2135-2146.

27. Ghent E, De Angelis M, VanRoestel K, Miller H, Anthony SJ. "We can't stay here forever" parents perceptions of transition

Pediatric Transplantation 2011: 15: 70.

28. BUFORD TA. Transfer of asthma management responsibility from parents to their school-age children. J Pediatr Nurs 2004: 19: 3-12.

29. FISHER HR. The needs of parents with chronically sick children: a literature review. J Adv Nurs 2001: 36: 600-607.

30. HuMmeLINCK A, Pollock K. Parents' information needs about the treatment of their chronically ill child: a qualitative study. Patient Educ Couns 2006: 62: 228-234.

31. BRODIE L, CRISP J, MCCORMACK B, WILSON V, BERGIN P, FULHAM C. Journeying from Nirvana with mega-mums and broken hearts: the complex dynamics of transition from paediatric to adult settings. International Journal of Child and Adolescent Health 2011: 3: 217-226.

32. LEONARD BJ, GARWICK A, ADWAN JZ. Adolescents' perceptions of parental roles and involvement in diabetes management. J Pediatr Nurs 2005: 20: 405-414.

33. Meah A, CALleRY P, MiLnes L, Rogers S. Thinking 'taller': sharing responsibility in the everyday lives of children with asthma. J Clin Nurs 2010: 19: 1952-1959.

34. COULTER A. Patient engagement - what works? The Journal of Ambulatory Care Management 2012: 35: 80-89.

35. KIECKHEFER GM, TRAHMS CM. Supporting development of children with chronic conditions: from compliance toward shared management. Pediatr Nurs 2000: 26: 354-363.

36. HENTINEN M, KYNGAS H. Factors associated with the adaptation of parents with a chronically ill child. J Clin Nurs 1998: 7: 316-324.

37. POWER TG, DAHLQUIST LM, THOMPSON SM, WARREN R. Interactions between children with juvenile rheumatoid arthritis and their mothers. J Pediatr Psychol 2003: 28: 213-221.

38. ORGANISATION WH. Health for the world's adolescents - a second chance in the second decade.

39. ShaW KL, Watanabe A, RANKIn E, McDonagh JE. Walking the talk. Implementation of transitional care guidance in a UK paediatric and a neighbouring adult facility. Child Care Health Dev 2014: 40: 663-670.

40. HART RI, Foster HE, McDonagh JE, et al. Young people's decisions about biologic therapies: who influences them and how? Rheumatology (Oxford) 2015: 54: 1294-1301.

41. Amaria K, Stinson J, CUllen-Dean G, Sappleton K, Kaufman M. Tools for addressing systems issues in transition. Healthc $Q$ 2011: 14 Spec No 3: 72-76.

42. NAKHLA M, DANEMAN D, FRANK M, GUTTMANN A. Translating transition: a critical review of the diabetes literature. J Pediatr Endocrinol Metab 2008: 21: 507-516. 
43. MCDONAGH JE, SHAW KL, SOUTHWOOD TR. Growing up and moving on in rheumatology: development and preliminary evaluation of a transitional care programme for a multicentre cohort of adolescents with juvenile idiopathic arthritis. J Child Health Care 2006: 10: 22-42.

44. AKRE C, RAMELET AS, BERCHTOLD A, SURIS JC. Educational intervention for parents of adolescents with chronic illness: a pre-post test pilot study. Int J Adolesc Med Health 2015: 27: 261-269.

45. KINGSNORTH S, GALL C, BEAYNI S, RIGBY P. Parents as transition experts? Qualitative findings from a pilot parent-led peer support group. Child Care Health Dev 2011: 37: 833-840. 
Table 1. Demographic information for parents and young people

\begin{tabular}{|c|c|c|c|c|c|}
\hline $\begin{array}{c}\text { Gender of } \\
\text { parent }\end{array}$ & $\begin{array}{c}\text { Gender of } \\
\text { patient }\end{array}$ & $\begin{array}{l}\text { Age of } \\
\text { patient } \\
\text { (years) }\end{array}$ & $\begin{array}{c}\text { Indication } \\
\text { for LTX }\end{array}$ & $\begin{array}{l}\text { Age at } \\
\text { LTX } \\
\text { (years) }\end{array}$ & $\begin{array}{l}\text { Transition status and } \\
\text { time since transfer, if } \\
\text { applicable }\end{array}$ \\
\hline Female & Female & 15.2 & Chronic & 9.2 & Pre-transfer \\
\hline Female & Male & 16.3 & Acute & 15.1 & Pre-transfer \\
\hline Male & Male & 16.9 & Chronic & 4.9 & $\begin{array}{l}\text { Post-transfer } \\
\text { (3 months) }\end{array}$ \\
\hline Female & Male & 18.7 & Chronic & 12.8 & Pre-transfer \\
\hline Male & Male & 19.8 & Chronic & 7.5 & Pre-transfer \\
\hline Female & Female & 21.2 & Acute & 0.9 & $\begin{array}{l}\text { Post-transfer } \\
\text { (3 years) }\end{array}$ \\
\hline Male & Female & 21.8 & Chronic & 12.1 & $\begin{array}{l}\text { Post-transfer } \\
\text { (3 years) }\end{array}$ \\
\hline Female & Female & 22.0 & Acute & 15.9 & $\begin{array}{l}\text { Post-transfer } \\
\text { (3 years) }\end{array}$ \\
\hline Female & Female & 25.1 & Chronic & 6.8 & $\begin{array}{l}\text { Post-transfer } \\
\text { (5 Years) }\end{array}$ \\
\hline
\end{tabular}


Table 2: Topic guide for use in the interviews with parents

- Experiences of having a child undergoing liver transplant (background of the experience, life with a young person with a transplant)

- Feelings about transition to adult services

- Exploration of how the young person is coping/will cope

- Exploration of how they (parents) are coping/will cope

- Support for parents and young people in transition 